\title{
Potential for Dose-escalation in the Post-prostatectomy Setting with Intensitymodulated Radiation Therapy: A Dosimetric Study Using EORTC Consensus Guidelines for Target Volume Contours
}

\author{
M. Studenski \\ Thomas Jefferson University and Hospitals
}

A. Harrison

Thomas Jefferson University and Hospitals

S. Anamalayil

Thomas Jefferson University and Hospitals
A. Harvey
Thomas Jefferson University and Hospitals. Follow this and additional works at: https://jdc.jefferson.edu/bodinejournal
Trąhylsithe Oncology Commons Themas Jefferson University and Hospitals to this document benefits you

\author{
Ree nextpage for additional authors \\ Studenski, M.; Harrison, A.; Anamalayil, S.; Harvey, A.; Trabulsi, E.; Xiao, Y.; Yu, Y.; Dicker, A. P.; and \\ Showalter, T. N. (2010) "Potential for Dose-escalation in the Post-prostatectomy Setting with \\ Intensitymodulated Radiation Therapy: A Dosimetric Study Using EORTC Consensus Guidelines for Target \\ Volume Contours," Bodine Journal: Vol. 3 : Iss. 1 , Article 42. \\ DOI: https://doi.org/10.29046/TBJ.003.1.041 \\ Available at: https://jdc.jefferson.edu/bodinejournal/vol3/iss1/42
}

This Article is brought to you for free and open access by the Jefferson Digital Commons. The Jefferson Digital Commons is a service of Thomas Jefferson University's Center for Teaching and Learning (CTL). The Commons is a showcase for Jefferson books and journals, peer-reviewed scholarly publications, unique historical collections from the University archives, and teaching tools. The Jefferson Digital Commons allows researchers and interested readers anywhere in the world to learn about and keep up to date with Jefferson scholarship. This article has been accepted for inclusion in Bodine Journal by an authorized administrator of the Jefferson Digital Commons. For more information, please contact: JeffersonDigitalCommons@jefferson.edu. 


\section{Potential for Dose-escalation in the Post-prostatectomy Setting with Intensitymodulated Radiation Therapy: A Dosimetric Study Using EORTC Consensus Guidelines for Target Volume Contours}

\section{Authors}

M. Studenski, A. Harrison, S. Anamalayil, A. Harvey, E. Trabulsi, Y. Xiao, Y. Yu, A. P. Dicker, and T. N. Showalter 


\title{
Potential for Dose-escalation in the Post-prostatectomy Setting with Intensity- modulated Radiation Therapy: A Dosimetric Study Using EORTC Consensus Guidelines for Target Volume Contours
}

\author{
Studenski, M., ${ }^{1}$ Harrison, A., ${ }^{1}$ Anamalayil, S., ${ }^{1}$ Harvey, A., ${ }^{1}$ Trabulsi, E., ${ }^{2}$ Xiao, Y., ${ }^{1}$ Yu, Y., ${ }^{1}$ Dicker, A.P., ${ }^{1}$ and Showalter, T.N. ${ }^{1}$ \\ ${ }^{1}$ Department of Radiation Oncology, Thomas Jefferson University and Hospitals, Philadelphia, PA \\ 2Department of Urology, Thomas Jefferson University and Hospitals, Philadelphia, PA
}

\section{Purpose}

Radiation therapy (RT) is delivered after radical prostatectomy (RP) for prostate cancer (PC). Although intensity modulated radiation therapy (IMRT) has become standard in definitive RT for PC, dosimetric data in support of post-RP IMRT are limited. This study was designed to quantify benefits of IMRT versus 3D conformal RT (3DCRT) with respect to dose sparing of rectum and bladder and target volume coverage. Motivated by the desire to deliver higher radiation doses and to quantify the dosimetric impact of IMRT, we retrospectively analyzed images in order to: 1) identify a preferred IMRT beam arrangement; 2) evaluate the dosimetric advantages of IMRT compared to 3DCRT; and 3) assess the variation of dosimetric parameters during the RT course using conebeam CT (CBCT) images.

\section{Methods}

Twenty patients who received post-RP RT at our institution were identified. All patients were treated with 4 -field 3DCRT plans (68.4 Gy to a minimum of $95 \%$ coverage). A single observer delineated all volumes to comply with EORTC consensus guidelines. The CTV was expanded $7 \mathrm{~mm}$, except $5 \mathrm{~mm}$ posteriorly, to create the planning target volume (PTV). To identify optimal IMRT beam arrangements, 10 patients were planned with both 5- and 9-field, coplanar IMRT plans. Then, 9-field IMRT plans (72.0 Gy) were completed for the remaining patients. Differences of DVH values between IMRT and 3DCRT plans were evaluated using 2-tailed paired t-tests. CBCT data was used to evaluate rectal volume and dose throughout treatment.

\section{Results}

The 9-field IMRT plans (vs. 3DCRT) improved mean bladder dose values (31.23 Gy vs $34.89 \mathrm{~Gy}, \mathrm{p}=0.003)$ and V65Gy (15.4\% vs $21.4 \%$, $\mathrm{p}=0.06)$. Additionally, 9-field IMRT reduced rectal endpoints: mean (31.58Gy vs $36.14 \mathrm{~Gy}, \mathrm{p}=6.8 \mathrm{E}-07$ ), V75\% (24.4\% vs $31.0 \%$, $\mathrm{p}=0.0005$ ), and V65Gy (10.5\% vs $20.0 \%, \mathrm{p}=1.08 \mathrm{E}-8)$. Advantages of IMRT were at the cost of small increases in maximum dose delivered to the bladder
(73.3 Gy vs $71.3 \mathrm{~Gy}, \mathrm{p}=0.0004)$ and the rectum $(72.8 \mathrm{~Gy}$ vs $71.1 \mathrm{~Gy}$, $\mathrm{p}=0.001$ ) compared to 3DCRT. The 9-field and 5-field IMRT plans had comparable PTV coverage. The 9-field IMRT produced minimal improvements in mean rectal doses, but had lower maximum dose to $1 \mathrm{cc}$ volume (71.58 Gy vs $73.18 \mathrm{~Gy}, \mathrm{p}=0.003)$. CBCT images $(\mathrm{n}=132)$ were analyzed for 8 patients; rectum mean dose and V65 were also improved by IMRT on these scans. IMRT allowed dose escalation to 72.0 Gy while maintaining similar bladder and rectum mean doses, V65, and V40 compared to 3DCRT to $68.4 \mathrm{~Gy}$.

\section{Conclusion}

IMRT improves dosimetric parameters for the rectum and bladder, which may reduce toxicity and allow dose-escalation after radical prostatectomy. Future studies should determine whether these dosimetric improvements translate into improved clinical outcomes for PC patients. 